\title{
Cultural Awareness in the Teaching of Shanghainese in Shanghai Kindergartens
}

\author{
Yan-Yan Li \\ Human Resources Department, Tianhua College \\ Shanghai Normal University \\ Shanghai, China
}

\begin{abstract}
The purpose of this study is to examine Shanghai cultural awareness activities in the teaching of Shanghainese in Shanghai kindergartens in China and to share recommendations for further promoting cultural awareness activities, in efforts to maintain and develop minority languages or Chinese dialects in China. This study used the case study approach and Kindergarten $Q$ was identified to be the case. The results suggest that cultural awareness activities should play a significant role in promoting the teaching of minority languages or Chinese dialects at schools. However, there is much more that needs to be done by schools in enhancing cultural awareness activities, such as increasing, developing and cultivating more cultural awareness activities.
\end{abstract}

Keywords-Cultural Awareness; Dialect; Teaching of Shanghainese; Kindergarten

\section{INTRODUCTION}

In recent years, with the successful promotion of Putonghua, some minority languages and local dialects are on the decline, some even to the point of vanishing in China. Dialects are an essential part of cultural heritage which reflect local cultural diversity, and as a group they reflects national cultural diversity. The Chinese government realized the importance of preserving local dialects and is beginning to make efforts to preserve the dialects.

Shanghainese is the spoken local dialect in Shanghai. Shanghai is the largest city in China. It has more than 24 million people as of 2019. Shanghai is one of the most significant cultural and financial centers in China, including a major shipping port as well. Shanghai culture is known by the nickname of "Hai Pai culture."[5] Hai Pai culture is a combination of Chinese and Western cultures. It is characterized by its fine arts, clothes, and Huju (Shanghainese opera). Shanghainese is an essential part of Hai Pai culture.

Together with the Chinese central government, the Shanghai government is also making notable efforts to combat the loss of Shanghainese from kindergarten all the way through university in Shanghai[2]. It is acknowledged widely that Shanghainese is being preserved well and expansively much better than other dialects in China, possibly due to great efforts made by the Shanghai government [3].

A language can't be separated from its attendant culture. Otherwise, it is like a body without a soul. Therefore, to develop heritage cultural awareness alongside language teaching is a key element in minority language education [1].
Cultural awareness is the foundation of communication and it involves the ability to stand back from ourselves and become aware of our cultural values, beliefs and perceptions.

In Wales, the "Curriculum Cymreig" (the Welsh Cultural Curriculum) was developed to foster cultural awareness. Curriculum Cymreig endeavors to reflect the whole range of historical, social, economic, cultural, political and environmental influences that have shaped contemporary Wales. This involves giving students a sense of place and heritage, of belonging to the local and wider community with its own traditions, a strong Welsh identity, access to the literature of Wales, differences and traditions in use of the Welsh and English languages in Wales, and the distinctive nature of Welsh music, arts, crafts, technology, religious beliefs and practices [4]. The "Curriculum Cymreig" helped students to "identify their sense of Welshness" and to create a "greater sense of belonging to their local community and country" (Developing the Curriculum Cymreig, 2003).

The Shanghai government officially issued a paper on the teaching of Shanghainese in Shanghai kindergartens in May 2013 as a way of maintaining and developing Shanghainese. As a result, 20 public kindergartens were selected to start the teaching of Shanghainese on a trial basis in September, 2014. The purpose of this study is to examine Shanghai cultural awareness activities in the teaching of Shanghainese in Shanghai kindergartens in China and to share recommendations for further promoting cultural awareness in language teaching, in efforts to maintain and develop minority languages or Chinese dialects in China.

\section{METHODS}

I employed a purposeful sampling strategy to identify Kindergarten Q from the 20 selected kindergartens as a case to conduct my study. Kindergarten $\mathrm{Q}$ developed quite a number of Shanghai cultural awareness activities to assist the teaching of Shanghainese. In Kindergarten Q, the principal recommended one third grade class in the kindergarten. Two teachers were responsible for each classroom. Thus, I identified two kindergarten teachers in one classroom. The kindergarten teachers recommended two parents, one was a native Shanghainese and the other a New Shanghainese. Thus, one principal, two kindergarten teachers, and two parents were involved in this study. 


\section{DATA ANALYSIS}

In terms of data collection procedures, I collected data through observations, interview and documents. I used the process of triangulation and member checking to validate the accuracy of the data. The data analysis procedures in this study were guided by the purpose and the pattern, theme and content analysis of this analytic strategy. The strategy used for this study provided a framework for the overall direction of the study and guided decisions and actions in order to integrate individual activities toward a common purpose.

\section{RESULTS}

Regarding the teaching of Shanghainese, Shanghai culture is stressed in the implementation of the teaching of Shanghainese in Kindergarten Q. Principal Wen is in charge of the teaching of Shanghainese. The third-grade Seashell class in Kindergarten $\mathrm{Q}$ was involved in this study. Teacher $\mathrm{Xu}$ and Teacher Cao are responsible for the Seashell class.

Shanghai cultural awareness is fostered by playing Old Shanghai alley games, playing socio-dramatic games in Shanghainese, singing the ballads in Shanghainese, classroom visits and fieldtrips (Table I).

TABLE I. SHANGHAI CULTURAL AWARENESS ACTIVITIES IN KINDERGARTEN Q

\begin{tabular}{|c|c|c|c|c|c|}
\hline Name & \multicolumn{5}{|c|}{ Shanghai Cultural Awareness Activities } \\
\hline $\begin{array}{c}\text { Kindergarten } \\
\text { Q }\end{array}$ & $\begin{array}{l}\text { Playing } \\
\text { Old } \\
\text { Shanghai } \\
\text { Alley } \\
\text { games }\end{array}$ & $\begin{array}{c}\text { Playing } \\
\text { Socio-dramatic } \\
\text { Games in } \\
\text { Shanghainese }\end{array}$ & $\begin{array}{l}\text { Singing the } \\
\text { ballads in } \\
\text { Shanghainese }\end{array}$ & $\begin{array}{c}\text { Classroom } \\
\text { visits }\end{array}$ & Fieldtrip \\
\hline
\end{tabular}

\section{A. Playing Old Shanghai Alley Games}

Old Shanghai alley games are a part of Shanghai culture. It has been established that children learn through play. Playing Old Shanghai alley games is one way to learn Shanghai culture. Old Shanghai alley games are the games once played in the alleys in Old Shanghai. With regard to playing Old Shanghai alley games, Kindergarten Q set up some wood archways of alleys, some mock cardboard buildings, and tile walls of Shikumen on the street of Old Shanghai (a natural learning environment where the children communicated with each other in Shanghainese naturally and experience Shanghai culture) in Xiao'an Square. Children played some old Shanghai alley games, such as hopscotch, marbles (Involving a cardboard box with grooves on it, and children roll the marble into the grooves on the cardboard box), a blindfold, cards, a jump rope, etc.

The children enjoyed playing the Old Shanghai alley games that once were played by their parents in their childhood. Possibly, Shanghainese interested them more. As Teacher Sun stated:

It's not difficult for the children to play those old alley games. When the children are playing the games, they get to know the people's life in Old Shanghai, which stimulates their interests in learning Shanghainese. Shanghai culture interested the children as well. When the children were "shipping" the rice or the coal, they needed to overcome some challenges regarding height and distance. However, they truly could experience the hard life of the people in those old days.

Some research shows that learning language and culture together is a shortcut to master a language (Cai, 2010). By learning more about Shanghai culture, the children get to know more about Shanghai, become familiar with and appreciate its history, and become proud of being a part of Shanghai. More importantly, when the children are playing Old Shanghai alley games, they are more likely to speak Shanghainese.

\section{B. Playing Socio-dramatic Games in Shanghainese}

Some symbolic settings representing Old Shanghai were also displayed on the Old Shanghai Street, such as Nanjing Barbershop, a grocery store, rickshaws, Wangkai PhotoShop, Huifeng Bank, Seventy-Two Lodgers (a hotel), shoe polishers, knife and scissors sharpeners, and a snack shop, etc. The children played socio-dramatic games in Shanghainese on the Old Street once a week. For example:

Two boys were playing at the shoe polishers. A "shoe boy" was crying out for business in Shanghainese by imitating the cry that a real shoe boy in Old Shanghai would do:

Shoe Boy: "Polish shoes?” (A “customer” came near.)

Shoe Boy: "Good morning! Do your shoes need polishing?"

Customer: "Yes, they do. How much?"

Shoe Boy: "Five yuan.”

Customer: "Ok. Go ahead."

Shoe Boy: "Please sit down. Put your left foot on the stand." (The "shoe boy" started to polish the shoes with a wiper cloth.)

Shoe Boy: "Done, right foot."

Customer (constantly): “Are you done? Please go quick. I have got to go to the barbershop."

Shoe Boy: "I see. One minute.”

By playing socio-dramatic games in Shanghainese, the children were speaking and learning Shanghainese in a specific context. More than that, the children experienced Shanghai culture. As Principal, Wen, stated:

The children played the socio-dramatic play on the street of Old Shanghai and experienced the glamour of Shanghainese and Shanghai culture at the same time, which may leave some trace on children's minds.

Children love playing socio-dramatic games very much. Old Shanghai Street creates a favorable environment for the children to learn Shanghainese with more interactions with others and teachers and to gain Shanghai cultural experiences. 


\section{Singing the Ballads in Shanghainese}

Ballads in Shanghainese were popular between the 1930s and the 1960s (Wu, 2010). At that time, there were many alleys. Usually, people gathered in the alleys for coolness in summer and for children to play games. When children were playing games, they sang ballads in Shanghainese.

Two ballads in Shanghainese were played in the classroom every week together with pictures and words on the screen in the Seashell class. Sometimes, learning the ballads in Shanghainese was combined with playing old alley games and performance in Kindergarten Q. Some Old Shanghai alley games were accompanied ballads in Shanghainese. When the children were playing Old Shanghai alley games, they learned the accompanying ballads in Shanghainese.

Singing the ballads in Shanghainese proves to be effective in generating children's interest in learning the language. By nature, children are crazy about singing and dancing. As a result, it becomes a lot easier for children to learn Shanghainese. More importantly, children get to know the stories behind the ballads in Shanghainese, gain some cultural experience, and perhaps become proud to be Shanghainese.

\section{Classroom Visits}

Parents and grandparents were invited to tell stories in Shanghainese or perform Huju, etc. Those children whose parents were invited to the class were particularly excited about that. One native Shanghainese parent, Zhu, stated:

My son was proud to see me show talents in front of his classmates. After I performed Huju in his class, my son seemed to have more interest in speaking Shanghainese at home.

One grandmother who visited the class had been a famous woman in the social circles in Old Shanghai. She brought a picture of herself in her youth. She was wearing a nice chi-pao and told children how women behaved in Old Shanghai (between 1912 and 1949).

Women in Old Shanghai were well-mannered, elegant, gentle, fashionable and feminine. I usually prepared three dresses for one day. I wore a short-sleeved sweater in the morning, a chi-pao for going out in the afternoon, and a Western styled long dress for entertaining visitors at night. My parents educated me on the importance of a balanced diet. The time for breakfast, afternoon tea, and dinner were all rigorously observed. I was not allowed to play with tableware at the table nor talk with food in my mouth. If the soup was hot, I was told not to use my mouth to blow on it.

When the grandmother told her story, the children listened attentively, some even with their mouths open. It demonstrated that the children understood and were interested in the story.

\section{E. Fieldtrip}

Additionally, the parents were encouraged to take their children on fieldtrips within Shanghai, such as to the Oriental Pearl Building, Shikumen, and Chenghuang Temple. There is a great museum underneath the Pearl Building with all the replicas of old Shanghai streets. So far there are six short trip lines in Shanghai. Parents were also encouraged to take these short trips with their children. After these fieldtrips, the children shared the pictures and their thoughts on WeChat, a social media application similar to Twitter. In this way, the children got to know more about Shanghai and its culture.

To sum up, Shanghai cultural awareness is employed with an attempt to create a natural learning environment for children to learn Shanghainese. However, there is much more that needs to be done in creating a natural learning environment and for there to be a sufficient quality Shanghai cultural awareness activities in helping children learn Shanghainese.

\section{CONCLUSIONS}

First, there is a need to increase the proportion of Shanghai cultural awareness activities in the teaching of Shanghainese.

Second, there is a need to develop more Shanghai cultural awareness, such as enacting social conventions, cultural rituals and traditions. Shanghai cultural awareness activities increase in difficulty according to children's ages.

Third, Shanghai cultural awareness is still at its infant stage, segmented and unsystematic. There is a need to make efforts to develop a curriculum specifically focused on fostering Shanghai cultural awareness.

Last, parents need to be involved. The more parents are involved, the stronger Shanghai cultural awareness will be. Different ways need to be explored to motivate parents to be involved in Shanghai cultural awareness activities.

Shanghai cultural awareness activities should be an integral part of the teaching of Shanghainese in Shanghai kindergartens. Shanghainese and Shanghai culture are inseparable. Schools must bear in mind the necessity of teaching both language and culture together. In addition, children should be taught to celebrate diversity, to become culturally aware.

It is hoped that cultural awareness activities will give full play to their role as a bridge and proactively contribute to the teaching of minority languages or Chinese dialects in China. Separation of culture and language is false. Minority language culture must be consciously included in language teaching and the overall physical and psychological environment of the school.

\section{REFERENCES}

[1] Byram, M.. Cultural identities in the multilingual classroom. In J. Cenoz \& F. Genesee (eds), Beyond Bilingualism: Multilingualism and Multilingual Education. Clevedon: Multilingual Matters. 1998.

[2] Cai, Jia. Comprehensible Input in English Teaching and Learning. College of Foreign Language, West-China Normal University. 2010.

[3] Chen, Yingyi. The Position of Dialects in Mother Tongue Curriculum and Its Teaching Strategy. Nanjing Normal University. 2012.

[4] Estyn. Y Cwricwlwm Cymreig. The Welsh Dimension of the Curriculum of Wales: Good Practice in Teaching and Learning. Cardiff: ESTYN. 2001.

[5] $\mathrm{Xu}$, Shenglan. The Culture of Shanghai. Retrieved from http://www.chinaculture.org/gb/en/2006-08/28/content_85051.htm. 2006 